\title{
Congenital hypothyroidism due to developmental anomaly
}

INSERM

\section{Source}

INSERM. (1999). Orphanet: an online rare disease and orphan drug data base. Congenital hypothyroidism due to developmental anomaly. ORPHA:95711

Thyroid dysgenesis is a type of primary congenital hypothyroidism (see this term), a permanent thyroid hormone deficiency that is present from birth. 